EF intervention in preterm children

\title{
Improvement of executive functions after the application of a neuropsychological intervention program (PEFEN) in pre-term children
}

Abbreviated title: EF intervention in preterm children

Authors:

Olga García-Bermúdez ${ }^{1,2}$; Francisco Cruz-Quintana ${ }^{2}$; Miguel Pérez-García ${ }^{2}$; Natalia Hidalgo-Ruzzante ${ }^{2}$;Manuel Fernández-Alcántara ${ }^{2,3^{*}} \& \mathrm{M}^{\mathrm{a}}$ Nieves Pérez-Marfíl ${ }^{2 .}$

${ }^{1}$ University of Jaén, Spain.

${ }^{2}$ Mind, Brain and Behavior Research Center (CIMCYC), University of Granada, Spain.

${ }^{3}$ Department of Health Psychology, University of Alicante, Spain.

Accepted for publication in Children and Youth Services Review $22^{\text {nd }}$ October 2018

*Corresponding author:

Dr. Manuel Fernández Alcántara. Departamento de Psicología de la Salud. Universidad de Alicante, San Vicente del Raspeig, 03690 Alicante (España), Correo Electrónico: mfernandeza@ua.es

Conflict of interests:

The authors declare no conflict of interest 
EF intervention in preterm children

\title{
Improvement of executive functions after the application of a neuropsychological intervention program (PEFEN) in pre-term children
}

\begin{abstract}
Prematurity is one of the most prevalent health problems in developed countries. It is associated with important clinical and educational consequences, problems in activities of daily life, as well as alterations in different domains of executive functions (EF).The objective of the present study was to evaluate the effectiveness of a stimulation program for the EF (PEFEN Program) in a group of premature children and compare the effects with a control group, who worked with routine curricular skills. The participants were children aged 4 and 5 years, born preterm between 32 and 37 weeks of gestation with a weight between 1500-2499 grams, without severe chronic pathology, or disability equal to or greater than $33 \%$ (mental, sensorial and/or motor). The participants were evaluated individually using the BENCI, CUMANIN, and BRIEF-P neuropsychological tests, before and after both interventions. The results showed that the preterm-children who received the PEFEN program significantly improved in the domains of verbal understanding, phonic fluency, verbal fluency, working memory, visual memory, verbal memory, rhythm, and attention, in comparison with the control group. It is recommended to implement programs such as PEFEN to improve the development of $\mathrm{EF}$ in the school environment and prevent the deficit in populations at risk. Key words: prematurity, children, neuropsychology, executive functions, earlystimulation, mindfulness
\end{abstract}


EF intervention in preterm children

\section{Highlights}

- The application of EF stimulation programs improves neuropsychological performance in preterm children.

- Neuropsychological domains such as memory, attention and EF improve after the application of the program.

- The PEFEN program has shown its usefulness in premature children. 
EF intervention in preterm children

\section{Introduction}

The executive functions (EF) are fundamental cognitive skills for achieving good performance in life, as well as in the school and social environment, allowing people to face new and complex situations (Lezak, 2004). At the age of 5 years the three key components of EF have already been partially developed, these being working memory, inhibition, and cognitive flexibility (Matthew, Davidson, Amso, Anderson \& Diamond, 2006). Working memory involves the monitoring, manipulation, and updating of information; whilst inhibition refers to the ability to deliberately and precisely inhibit the production of automatic responses when the situation requires it; whilst cognitive flexibility allows for switching effectively between different mental operations (Miyake et al., 2000, Sastre-Rivas, 2009).

Intervention programs that have focused on EF in school children have revealed that training programs in creativity, flexibility, self-control and discipline bring about improvements in both their academic results and their daily lives (Diamond, 2013). In addition, the poorer the initial performance of the children, the greater the benefit they receive after training (Diamond, 2013, Diamond, Barnett, Thomas \& Munro, 2007, Diamond \& Lee, 2011). The literature also reports that in order to protect children from the negative effects of certain adverse experiences (toxic stress), it is fundamental, among other things, to encourage training in specific skills with special emphasis on EF, along with emotional and behavioral self-regulation (Shonkoff, 2010; Shonkoff et al., 2011; Shonkoff, Richter, Van der Gaag \& Zulfiqar, 2012).

In developed countries, prematurity is one of the most prevalent health problems during childhood and is considered to be one of the factors underlying the high risk of dependence and disability, with important consequences at both the family and social level (García-Bermúdez et al., 2012). The increase of premature births in 
EF intervention in preterm children

developed societies is associated with an increase in fertility treatments, the existence of better obstetric and neonatal care (which promotes a greater survival of even the most premature children), along with the advanced age and high stress levels of the mother (Davidoff, et al., 2006, Liu, et al., 2016, Nogueira-Cruz, Laynez-Rubio, Cruz-Quintana \& Pérez-García, 2012). The immaturity of the biological systems and morphological and functional characteristics of the premature child makes it more likely that they will present complications in their short, medium, and long term cognitive development (Narberhaus et al., 2007, Sastre Rivas, 2009).

According to the World Health Organization (2016), a baby that is born alive before 37 weeks of gestation is considered premature. Premature children are divided into three categories according to gestational age and birth weight: extreme preterm ( $<28$ weeks and weighing less than $1000 \mathrm{~g}$ ), very premature $(28$ to $<32$ weeks and weighing less than $1500 \mathrm{~g}$ ) and moderate-late preterm (32 to $<37$ weeks and weighing less than $2.500 \mathrm{~g})$.

The majority of studies on the consequences of prematurity have focused on the so-called very premature and extreme children, comparing them with full-term children. The literature reports that these two groups show greater delays in their neurocognitive development including: lower IQ, an increased risk of disability such as moderate mental retardation or cerebral palsy, greater respiratory problems, apnea, intraventricular hemorrhages, anemia, motor retardation, and visual problems (Bayless, Pit-ten Cate \& Stevenson, 2008; Begega et al., 2010). In addition, school problems associated with neuromotor, cognitive, language and behavioral delays are frequently reported (Bhutta, Cleves, Casey, Cradock \&Anand, 2002, Böhm, Smedler \& Forssberg, 2004, Ortiz-Mantilla, Choudhury, Leevers \& Benasich, 2008, Wocadlo \& Rieger, 2007). EF and memory can also be affected by prematurity (Bayless \& Stevenson, 
EF intervention in preterm children

2007), with these problems remaining in adolescence (Lhaugen et al., 2010; Loe, Lee, Luna \& Feldman, 2011), and even in adulthood (Mathiasen, Hansen, Forman, Kessing \& Greisen, 2011, Narberhaus et al., 2007, Saavalainen et al., 2006, Tideman, 2000). In the case of the group of late preterm children or those of moderately low weight (1500-2499 g), they usually present, between 3 and 8 years of age, neuropsychological and neurosensory problems that can affect their learning (Begega et al., 2010), with deficits in verbal comprehension, perceptive reasoning, and processing speed being reported (García-Bermúdez, et al., 2012). Studies in the behavioral field have found these children to show greater hyperactivity, behavioral and psychomotor problems, less attention, greater learning difficulties, atypical behaviors, and greater externalizing problems (García-Bermúdez et al., 2012; Hornman, de Winter, Kerstjens, Bos \& Reijneveld, 2016; Reijneveld, De Kleine \& Van de Baar, 2006). At school age, there is also poorer executive functioning, particularly inhibition, working memory, task switching, selective attention, and sustained attention (Sastre-Rivas, 2009). Late preterm children usually do not receive specific interventions addressed to these domains or appropriate follow-up, in comparison with very premature children. Preventive interventions directed towards the stimulation of these neuropsychological domains and to the regulation of behavioral and emotional problems are highly recommended for this population (Nogueira-Cruz et al., 2012; Perales et al., 2014).

In short, the existing studies have revealed important differences in executive functioning between children born at full term and those born prematurely without neurological alterations. These findings also emphasize the importance of early intervention to improve cognitive and behavioral aspects (Spittle \& Treyvaud, 2016, Spittle et al., 2016). However, to our knowledge, there are no studies that have shown the effectiveness of applying EF stimulation programs in premature children at the 
EF intervention in preterm children

beginning of school age. As indicated above, at this age there are several neuropsychological deficits, including EF, which are linked to academic performance (Nogueira-Cruz et al., 2011) along with a higher probability of having psychological problems in adolescence (Hornmanet al., 2016; Shonkoff et al., 2011). Therefore, stimulation of the EF at this age is potentially of great clinical relevance.

Thus, the main objective of this study was to apply and evaluate the effectiveness of an EF stimulation program (PEFEN program: Cruz-Quintana et al., 2014) in a group of preterm children aged 4 and 5 years, in comparison with a control group. It is expected that the group of children who receive the intervention with the PEFEN program will show improved performance in EF with respect to children with similar characteristics who receive a program based on general work with curricular skills.

\section{Material and methods}

\subsection{Participants}

Initially, 80 pre-term children were recruited from the Complejo Hospitalario de Jaén (CHJ) (Spain). The following inclusion criteria were applied: (i) birth between 32 and 37 weeks of gestation and (ii) birth weight between 1500 and 2499 grams. The exclusion criterion was the existence of severe chronic pathology or disability equal to or greater than $33 \%$ (mental, sensory and / or motor). A total of 68 children (30 boys and 38 girls) participated in the entire study. Of the 12 children who withdrew, 2 were due to the death of the father, 3 due to illness, and the remaining participants were excluded for not attending at least $50 \%$ of the sessions.

At the beginning of the study the children were divided and assigned to two groups: the group that received neuropsychological intervention with the PEFEN

program (NIG Group), composed of 36 children (13 boys and 23 girls), and the group 
EF intervention in preterm children

that received general curricular intervention (CIG Group), composed of 32 children (17 boys and 15 girls). Assignment to each group was carried out as follows: 4 different schedules were offered for the development of the program and the parents choose one of them according to their availability, two corresponded to the NIG Group and another two to the CIG Group. At the time of choosing, the parents did not know which of the intervention programs corresponded to each schedule. Both groups were homogeneous in terms of all the socio-demographic variables analyzed (see Table 1).

Insert Table 1 here

\subsection{Instruments}

2.2.1. Socio-demographic data: this information was collected using both the clinical history and a semi-structured interview, and included the child's age in months, sex, weight, type of delivery, time of pregnancy, smoking during pregnancy, age of the mother, gestational age of the mother, family socioeconomic status and level of studies of the mother. Healthy habits such as school adjustment, the existence of other chronic diseases, a special diet, medication and the number of hours of sleep were also evaluated.

2.2.2. Test Factor " $g$ " (Cattell \& Cattel, 1973) that evaluates non-verbal aspects of intelligence in adults, based on the relationships between forms and figures. It is composed by four different sub-tests. In the first one ("Series") participants have 5 minutes to identify which figure follows a pre-established logical series. In the second sub-test ("Classification"), participants have to identify, from a set of five figures, which is different or has different characteristics (duration: five minutes). In the third sub-test ("Matrix") participants have to complete the figure with the option that matches with rest of the elements (duration: 4 minutes). Finally, in the last sub-test ("Conditions") participants have to choose the picture or figure that matches with the same conditions 
EF intervention in preterm children

of an example (duration: 4 minutes). In the present study, it was used to obtain an intelligence measure of the mothers. The reliability of the Spanish version ranges between $\alpha=.70$ and .80 , with test-retest values of $r=.50-.60$ (Cattel \& Cattell, 1990).

2.2.3. Evaluation of the effectiveness of the intervention program (pre-and post-):

- Battery for Computerized Neuropsychological Evaluation of Children (BENCI)

(Cruz-Quintana, Pérez-García, Roldan-Vílchez, Fernández-López \& Pérez Marfil,

2013). This battery of tests allows for a comprehensive assessment of the basic

neuropsychological domains: processing speed, visual-motor coordination, attention, language, memory, and EF. The battery is presented in a computerized format, which allows for standardized administration and the recording of data in an easy and reliable way (correct answers, errors, and reaction time), as well as being easy to execute and enjoyable for children. The BENCI includes 17 neuropsychological tests that require between 60 and 70 minutes to complete, with a break of 10 minutes in the middle of the session. In the case of the present investigation, the following tests were included: Figure Comprehension, Image Comprehension, Continuous Execution, Phonetic Fluidity, Semantic Fluidity, Working Memory, Verbal Memory, Visual Memory, and Abstract Reasoning. A brief description of each task is described below:

2.2.3.1. Figure Comprehension: After being shown a group of geometric images (small, medium, or large circles, triangles, or squares in different colors), the child must select the image that meets given criteria (shape, size, position and/or color). Correct responses are recorded.

2.2.3.2. Image Comprehension: After being shown a group of images (e.g., animals), the child must select the image that meets given criteria (animal, position, activity and/or color). Correct responses are recorded. 
EF intervention in preterm children

2.2.3.3. Continuous Execution: Blocks of letters appear on the screen, one after the other. The child is instructed to press a key when a given sequence is shown (for example, letter A following X). The remaining letters are distractors. The reaction time (in ms) and number of correct responses are recorded.

2.2.3.4. Phonetic fluency: The child has 60 seconds to state all the words he/she knows that start with a given letter. Correct responses are recorded.

2.2.3.5. Semantic fluency: The participant is told a semantic category (e.g., colors or animals) and is given 60 seconds to say aloud all of the words that it covers, recording correct responses.

2.2.3.6. Working memory: After listening to sequences of mixed numbers and colors, the child must repeat the numbers and colors (first the numbers, in ascending order, and then the colors, or vice-versa). Correct responses are recorded.

2.2.3.7. Verbal memory: After listening three times to the same series of words, the child must repeat aloud all words that he/she can remember. Correct responses in immediate (first and third test) and delayed recall and delayed recognition tests are recorded.

2.2.3.8. Visual memory: After being shown pictures of common objects, the child must state aloud all objects they can remember. Correct responses for immediate and delayed recall and delayed recognition tests are recorded.

2.2.3.9. Abstract reasoning: A group of a logical series is shown on the screen. The participant must select the element that completes the series, recording the correct responses.

The order of administration was the same for all participants, in accordance with the recommendations of Lezak et al. (2004).The BENCI battery has shown good psychometric properties in its Spanish version (Cruz-Quintana et al., 2013). The test- 
EF intervention in preterm children

rest reliability, assessed through Pearson correlation coefficients and Interclass correlation coefficients showed values that varied between $r=.97$ (in verbal memory recall) and $r=.34$ (visual memory immediate). Internal consistency using Cronbach's alfa also showed values ranging from $\alpha=.92$ in selective attention, to $\alpha=.62$ in simple reaction time task. The convergent validity (for example: Stroop Word Colour Test for the Inhibitory Control Task, Backward Digits for the Working Memory Task, RAVEN test for the Abstract Reasoning task and Spanish Adaptation of Californian Verbal Learning Test for Verbal Memory tasks) presents acceptable and significant correlations (between $r=.689$ and $r=.335$ ).

\subsubsection{Childhood Neuropsychological Maturity Questionnaire (CUMANIN) (Portellano,} Mateos \& Martínez, 2000). This is a paper-based questionnaire that allows for the simple and effective evaluation of several areas that are of great importance in detecting possible development difficulties in ages that coincide with the beginning of school, and are essential in the development of children: psychomotricity (11 items), language articulation (15), language expression (4), language comprehension (4), spatial structuring (12), visuo-perception (15), iconic memory (10) and rhythm (7). This test presents adequate values of internal consistency, with a Cronbach's alpha value that varies between $\alpha=.71$ and .92 for the different subscales (Portellano et al., 2000).

\subsubsection{Behavioral Evaluation of Executive Functioning - Children's Version (BRIEF-P)}

(Gioia, Isquith\& Guy, 2000). This is a paper instrument that is completed by the parents and evaluates various executive skills: inhibition (i.e. difficulties to regulate their behavior), flexibility (i.e. difficulties in task switching), emotional control (i.e. difficulties to regulate emotional responses), working memory (i.e. difficulties to retain information in the mind), planning and coherence (i.e. difficulties to anticipate events or future consequences). This version of the BRIEF-P, adapted to children from 2 to 5 
EF intervention in preterm children

years old, consists of 63 items corresponding to sentences that describe children's behaviors, which are evaluated as: never, sometimes, or frequently (Basuela-Herreras \& Luque-Cuenca, 2017). The BRIEF-P shows adequate values of internal consistency, with $\alpha$ values ranging between .79 and .93 for the different subscales (Veleiro\&Peralbo, 2014).

\subsection{Intervention Programs applied:}

\subsubsection{The Stimulation Program in EF for children, known as PEFEN (Cruz-Quintana} et al., 2014), administered to the neuropsychological intervention group (NIG). This program is based on various neuropsychological models (Diamond \& Lee, 2011; Shonkoff, 2010) and on the use of Mindfulness techniques. It is a versatile program for the stimulation of the EF in children from 4 to 6 years of age. It is composed of group activities that integrate various components (working memory, inhibition / self-control, flexibility, decision-making, and attention) introduced through play, as well as Mindfulness techniques adapted to children (Flook et al., 2010). The duration of the program is three months, with the difficulty of the program (low, medium, and high) increasing month by month.

The PEFEN complies with the general requirements that have been described when building programs for training in EF. On the one hand it defines the executive components to train day by day, and the tasks of the program exert an increasing demand on the child, with the activities being programmed to increase the difficulty each month with both group tasks and individual activities. On the other hand, it has, among others, tasks that entail changes to which the children are little accustomed or changes that have to be made more rapidly. The tasks include those in which they can make mistakes and thereby enable them to recognize such errors and restructure new responses; tasks focused on the inhibition of attention / action and the inhibition of 
EF intervention in preterm children

thoughts and emotions; tasks that involve maintaining concentration and actively working on working memory; and creativity activities that involve adopting different perspectives when faced with objects and / or situations (Cruz-Quintana et al., 2014; Diamond \& Lee, 2011).

The frequency and duration of the weekly sessions were adapted for the intervention with premature children. Each week, 2 hours and 30 minutes were invested in a single session (including a small 10-minute break) so that each level is composed of 4 sessions, with a total of 12 sessions. Some examples of activities included in the program are the following:

- "Orchestra": Its objectives are the coordination of actions and to train the control of motor behavior

- "Uses ": Flexibility, creativity, attention, and inhibition are trained.

- $\quad$ "The drawings speak": Creativity, inhibition, and self-control are trained.

- $\quad$ "Alternate Categories": Flexibility, change of criteria, working memory, and attention are trained.

- "Restless Tales": Flexibility, decision-making, and self-control of motor behavior are trained.

- $\quad$ "Mindfulness": The main objective is to achieve — through relaxation and attentional tasks involving sounds, objects, and movements — the training of attention and inhibition of behavior in the present moment.

\subsubsection{Training program in curricular skills for the CIG. To control the effect of the} presence of the therapist, this group received stimulation for general curricular skills, through computer and audiovisual resources. Examples of tasks were coloring numbers and letters, group reading of stories, as well as the viewing of different educational 
EF intervention in preterm children

videos. The children of the CIG group received the same number of sessions, each of which had the same duration as the group that received the PEFEN program.

\subsection{Procedure}

The study was approved by the Research Ethics Committee of the Hospital Complex of Jaén (CHJ). Once the project had been approved, the facilities could be accessed and the $\mathrm{CHJ}$ databases searched to recruit the participants. Before beginning the study, all parents were informed of the research objectives and gave informed written consent. The participants were selected through the "Aurora" database, the hospital information system of the CHJ. This system allowed for filtering the children's clinical records, incorporating the inclusion and exclusion criteria employed in this investigation. After reviewing the medical records, we obtained the data of these children (birth-related variables) and their family, after which we proceeded to invite them by letter to voluntarily participate in the investigation. Telephone calls were then made to confirm receipt of the letter and to directly explain the procedure and objective of the investigation. At the first appointment, they were presented with the Informed Consent for their voluntary signature, and the neuropsychological pre-assessment of the child (BENCI and CUMANIN Battery) was conducted. At the same time, whilst in another room, the parents completed the socio-demographic interview, Childhood Healthy Habits Questionnaire, Cattell Test Factor "g", and BRIEF-P.

Once the individual neuropsychological pre-evaluation of each child was completed, the parents were required to choose between 4 intervention schedules for their child, selecting the one that was best suited to their timetables, without any prior knowledge of the group to which the schedule belonged. Using this procedure, the children were assigned to the neuropsychological intervention groups (NIG) or to the curricular intervention groups (CIG). After the interventions, the families were again 
EF intervention in preterm children

called to conduct the individual neuropsychological post-evaluation of the children (BENCI, CUMANIN, and BRIEF-P).

Once the study was completed and data collected, the curricular intervention group received, in addition, the PEFEN Stimulation Program. Interested families were given an individualized report, which included the results obtained and relevant recommendations in each case.

\subsection{Data analysis}

A mixed factorial design was used with two independent variables: receiving the PEFEN Stimulation Program or not, which was a between-subject variable, and the time of evaluation (pre-post), which was the within-subject variable. Descriptive analyzes were conducted using means and standard deviations for the quantitative variables and frequencies for the qualitative variables. The differences between groups were analyzed using the $t$ test (for independent samples and quantitative variables) and the chi-square test for qualitative variables.

To check the effectiveness of the program, the different variables evaluated were compared according to scores on the BENCI, CUMANIN, and BRIEF-P batteries. For the analysis, a general linear model of repeated measures $(2 \times 2)$ was used, with two levels for the between-group factor, depending on whether the participants had followed the PEFEN program: Neuropsychological Intervention Group (NIG), or had followed a curricular skills program: Curriculum Intervention Group (CIG); and two levels for the within-subjects factor, corresponding to the two times of the evaluation (Pre and Post intervention). Cohen's delta was used as a measure of the effect size of the different groups. The data were analyzed with the statistical package SPSS 17.

\section{Results}

\subsection{Analysis of the BENCI Battery}


EF intervention in preterm children

When analyzing the results of the BENCI battery for the main effect of "time of evaluation" (changes in both groups between pre and post testing), we observed statistically significant differences in 13 of the 15 variables evaluated, including the subtests of: Verbal Comprehension (figures), Verbal Comprehension (images), Phonetic Fluidity, Semantic Fluidity, Working Memory, Verbal Memory (both in the first, third and delayed memory), Abstract Reasoning, Visual Memory (immediate, delayed, and recognition). These results appear to indicate that both groups improved between the pre - and post - tests (independently of the assigned intervention program), in most of the neuropsychological variables (see Table 2).

In the case of the interaction between time of the evaluation (pre-post) and group, this was found to be statistically significant for the Phonetic fluency subtest, F $(1,66)=4.77, p=.032$ (with a particularly large effect size for the NIG, $d=1.36$ ), and for the Delayed Visual Memory test, $\mathrm{F}(1,66)=6.79, p=.011, d=1.44$. Marginally significant differences were found for the variables of Working Memory, F $(1,66)=$ $3.60, p=.062$, (again, with a large effect size for the NIG, $d=1.37$ ), and for Delayed Verbal Memory, $\mathrm{F}(1,66)=3.83, p=.055$, with a significant effect size in the NIG group $(d=1.30)$. These results indicate a greater increase in the scores of these four subtests for the NIG group. For the other factors, no statistically significant effects were found after exploring the interaction (see Table 2).

Insert Table 2 here

\subsection{Analysis of the CUMANIN}

For CUMANIN, statistically significant improvements were observed between pre and post testing for all the subtests evaluated (see Table 3). Similarly, we identified a statistically significant interaction between time of the evaluation (pre-post) and group for the Total Score, $\mathrm{F}(1,66)=4.96, p=.029$, with a high effect size in the 
EF intervention in preterm children

NIGintervention group $(d=1.26)$; the Rhythm subtest, $\mathrm{F}(1,66)=13.31, p=.001, d=$ .70 ; Verbal fluency, $\mathrm{F}(1,66)=10.97, p=.002, d=2.53$; and a marginal effect for Attention, $\mathrm{F}(1,66)=3.70, p=.059, d=.73$. For the other factors, no statistically significant effects were found after exploring the interaction (see Table 3).

-Insert Table 3 here

\subsection{Analysis of the BRIEF-P (Parents)}

Finally, the differences for the factors evaluated by the BRIEF-P were analyzed. We found statistically significant differences for the Inhibition factor, for the time of testing $\mathrm{x}$ group interaction, $\mathrm{F}(1,66)=5.19, p=.026$, and for the time of testing, $\mathrm{F}(1,66)=5.18, p=.026$. These results are due to a decrease in inhibition scores for the GIC group, while in the NIG group they remain stable following the intervention. For the remaining variables evaluated with the BRIEF-P battery, no statistically significant differences were found (see Table 4).

-Insert Table 4 here

\section{Discussion}

The objective of this work was to apply and evaluate the effectiveness of a EF stimulation program (PEFEN Program) in a group of preterm children aged 4 and 5 years in comparison with a control group of premature children who did not receive such anintervention. The results reveal that children who had received the PEFEN program (NIG) showed improvements in their overall neuropsychological performance compared with those who had received the standard curricular program (CIG). In particular, positive changes were found in variables such as Verbal Comprehension (figures), Phonetic and Verbal Fluency, Working Memory, Visual Memory, Verbal Memory, Rhythm, and Attention. Regarding Continuous Performance, it should be noted that as the reaction time (RT) is slower, the number of correct 
EF intervention in preterm children

responses(CR)increased in the NIG group following the intervention. Finally, the children in the NIG group maintained stable inhibition scores across the test phases. These results indicate that the PEFEN program generates neuropsychological benefits in the population studied.

The literature reports a whole series of interventions aimed at improving cognitive development in children with the goal of training basic cognitive processes at the beginning of school learning (Segretin et al., 2016), implemented in child populations with variousprofiles such as typical development (Diamond \& Lee, 2011; Thorell et al., 2009), social vulnerability (Colombo \&Lipina, 2005, Diamond et al., 2007; Hughes \& Ensor, 2009) and clinical populations (Klingberg et al., 2005; McCandliss, Beck, Sandak , \&Perfetti, 2003; Stevens, Fanning, Coch, Sanders, \& Neville, 2008; Temple et al., 2003; Wilson, Revkin, Cohen, Cohen, \&Dehaene, 2006). Regardless of the characteristics of the indicated programs, there is a scarcity of data related to premature children or those of moderately low weight, as well as intervention programs focused on the improving EF in this population. In a study conducted in Spain with children with learning disabilities (Correa, FernándezAlcántara, Pérez-García, Laynez-Rubio \& Cruz-Quintana, 2017), improvements were reported in the performance of EF (specifically in the areas of cognitive flexibility and working memory) in a group of children with learning problems who participated in a stimulation program in EF compared with a control group without clinical problems. However, no differences were found in central variables such as attention. In the present study, the children in the NIG group showed significant changes in attentional aspects, which may be directly related to the inclusion of specific Mindfulness exercises in each of the intervention sessions. The inclusion of a specific module focused on Mindfulness is one of the most innovative features of the PEFEN program. Despite the fact that 
EF intervention in preterm children

scientific evidence suggests an improvement in executive functioning when this technique is used in childhood (Nadler, Cordy, Stengel, Segal \& Hayden, 2017), specific modules of Mindfulness are not found in other programs applied to both typical child population and populations with clinical problems other than prematurity.

In addition to the improvements in neuropsychological variables related to $\mathrm{EF}$, children who received the PEFEN Program showed stable scores in the inhibition dimension, which could be taken to indicate that the program also has a preventive effect in premature children, promoting self-control and regulatory skills, which can be altered in adolescence (García-Bermúdez et al., 2012). In this regard, the results obtained in this study are encouraging insofar as they provide specific information on the Spanish population of premature children, showing how the PEFEN program is effective as an intervention for EF in the studied risk population.

Similarly, the results reveal an effect of the time of testing in most of the variables evaluated. This seems to indicate better neuropsychological performance over the passage of time, which is consistent with the age of the children of the present study, who are in a critical period in the development of the various neuropsychological domains (Matthew et al. al., 2006; Miyake et al., 2000). Despite this pattern of results, the differences in the interactions between the time of evaluation and group seem to indicate that the PEFEN program promotes improvements in the different domains studied. This is of great relevance, since previous research has indicated how prematurity is a risk factor for presenting neuropsychological and cognitive alterations that interfere in the performance of those capacities necessary for learning, such as language and memory (Aarnoudse-Moens et al., 2009; Barre, Morgan, Doyle \& Anderson, 2011, Figueras \& Bosch-Galceran, 2010, Lezak, 2004, Maggiolo, Varela, Arancibia \& Ruíz, 2014, Narberhaus et al., 2007). In relation to EF in particular, the 
EF intervention in preterm children

lack of information has already been pointed out with regard to premature children, particularly at early ages (García-Bermúdez et al., 2012), although problems have been reported in functions such as planning, inhibition, interference (Sartre-Riba, 2009), working memory, and flexibility (Aarnoudse-Moens et al., 2009).

The results of the present investigation have important clinical implications. While there is little information about EF in premature children, this is practically nonexistent in relation to the effects of intervention programs. There is evidently a need to initiate not only follow-up programs but also intervention programs that cover the ages of 5 to 8 years. This age range is critical for the acquisition of reading, writing, and mathematical reasoning, areas in which premature children appear to show significant academic problems. In this regard, numerous studies report the relationship between EF and school performance, with working memory being one of the most studied capacities due to its relationship with the learning of subjects such as language, reading and writing, mathematics, and science (Arán-Filippetti \& Richaud de Minzi, 2011). The findings of this research could be useful both in the school environment for improving the development and learning of children, and also in the clinical context for preventing the possible negative patterns of development in certain risk populations.

\subsection{Limitations and future directions}

However, this study suffers from a series of limitations. First, the number of participants is low. Therefore, measures of the size of the effect have been included, which allow us to verify the effects of the program without depending on group size. Secondly, the study has focused on a very specific clinical population (late preterm infants), and so we should be cautious when extrapolating these results to other areas and clinical populations (very preterm children and non-premature children). Thirdly, 
EF intervention in preterm children

studies of a longitudinal nature are necessary to verify whether the long-term effects of the program are maintained.

\subsection{Conclusion}

In conclusion, the EF Stimulation Program (PEFEN) has shown to be an effective and versatile program of intervention for improving the development of executive functioning in children born prematurely. The group of premature children who received the PEFEN showed significant improvements in Verbal Comprehension (figures), Phonetic Fluency, Verbal Fluency, Working Memory, Visual Memory, Verbal Memory, Rhythm and Attention.

\section{References}

Aarnoudse-Moens, C. S. H., Weisglas-Kuperus, N., van Goudoever, J. B., \&Oosterlaan, J. (2009). Meta-analysis of neurobehavioraloutcomes in verypreterm and/or verylowbirthweightchildren.Pediatrics, 124, 717-728. doi: 10.1542/peds.20082816.

Arán-Filippetti, V.,\&Richaud de Minzi, M.C. (2011). Effects of a training program to increase reflexivity and planning in a school area at risk due to poverty.UniversitasPsychologica, 10, 341-354.

Barre, N., Morgan, A., Doyle, L. \& Anderson, P. (2011). Language abilities in children who were very preterm and/or very low birth weight: A meta-analysis. The Journal of Pediatrics, 158,766-74.doi: 10.1016/j.jpeds.2010.10.032

Bausela-Herreras, E., \& Luque-Cuenca, T. (2017). Evaluación Conductual de la Función Ejecutiva-Versión Infantil (BRIEF-P, versión española): fiabilidad y validez [Behavior rating inventory of executive function-preschool version (BRIEF-P, Spanish adaptation): reliability and validity]. Acta de Investigación Psicológica, 7, 2811-2822. 
EF intervention in preterm children

Bayless, S.J., Pit-ten Cate, I.M., \& Stevenson, J. (2008).Behaviourdifficulties and cognitive function in children born very prematurely.International Journal of BehaviouralDevelopment, 32, 199-206.

Bayless, S., \& Stevenson, J. (2007). Executive functions in school-age childrenborn very prematurely. Early Human Development, 83, 247-254.

Begega, A., Méndez-López, M., de Iscar,M.J., Cuesta-Izquierdo, M., Solís, G., Fernández-Colomer, B., ...,\& Arias JL. (2010). Assessment of the global intelligence and selective cognitive capacities in preterm 8-year-old children. Psicothema,22, 648-653.

Böhm, B., Smedler, A.C., \&Forssberg, H. (2004).Impulse control,working memory and other executive functions in preterm childrenwhen starting school.ActaPaediatrica, 93, 1363-1371.

Bhutta, A.T., Cleves, M.A., Casey, P.H., Cradock, M.M., \&Anand, K.J.(2002). Cognitive and behavioral outcomes of school-aged childrenwho were born preterm: A meta-analysis. JAMA, 288, 728-737.

Cattell, R. B., \& Cattell, A. K. S. (1973). Culture Fair Intelligence Tests: CFIT. Institute for Personality \& Ability Testing.

Cattell, R.B. \&Cattell, A.K.S. (1990).Test de factor "G" (escala 2 y 3) [Factor G test (scales 2 and 3)].Madrid: TEA

Colombo, J.A. \&Lipina, S.J. (2005). Hacia un programapúblico de estimulación cognitiva infantil.Fundamentos, métodos y resultados de unaexperiencia de intervención preescolar controlada. [Towards a public program of cognitive child stimulation: foundations, methods and results of a controlled preschool intervention experience].Buenos Aires: Editorial Paidós. 
EF intervention in preterm children

Correa, C., Fernández-Alcántara, M., Pérez-García, M., Laynez-Rubio, C.,\& CruzQuintana, F. (2017). Effects of an ExecutiveFunctions stimulation programme for childrenwithlearningdisabilities. Estudios de Psicología/Studies in Psychology,38, 537-543. doi:10.1080/02109395.2017.1295576

Cruz-Quintana, F., Pérez-García, M., Roldan-Vílchez, L.M., Fernández-López, A. \&Pérez Marfil, MaN. (2013). Batería de Evaluación Neuropsicológica Infantil (BENCI). Granada. (Procedencia: GR-126-11. Nº de Registro: 201199900323736).

Cruz-Quintana, F., Pérez García, M., Pérez Marfil, M. N., Pérez García, P., Hidalgo Ruzzante, N, Pérez Lobato, R., ....\&García Bermúdez, O., (2014). Programa PEFEN: Programa de Estimulación en Funciones Ejecutivas para Niños/as. [PEFEN Program]Granada: Ediciones Sider.

Davidoff, M. J., Dias, T., Damus, K., Rusell, R., Bettegowsa, V. R., Dolan,S., ..., Petrini, J. (2006). Changes in the gestational age distributionamong U.S. singleton births: Impact on rates of late preterm birth, 1992to 2002. Seminars in Perinatology, 30, 8-15. doi: 10.1053/j.semperi.2006.01.009.

Diamond, A., Barnett, W. S., Thomas, J. \& Munro, S. (2007). Preschool program improves cognitive control. Science, 318, 1387-1388. doi: $10.1126 /$ science. 1151148

Diamond, A. (2013). Executive Functions. The Annual Review of Psychology, 64, 135168. doi: 10.1146/annurev-psych-113011-143750

Diamond, A., \& Lee, K. (2011). Interventions and programs demonstrated to aid executive function development in children 4-12 years of age. Science, 333, 959-964. doi: 10.1177/0963721412453722 
EF intervention in preterm children

Figueras, M.,\& Bosch, L. (2010). Capacidades de discriminación fonética de un contraste vocálico nativo en el prematuro.[Phoneticdiscriminationcapabilities of a nativevowelcontrast in thepremature]Psicothema,22, 669-676.

Flook , L., Smalley, S.L., Kitil, M.J., Galla, B.M., Kaiser-Greenland, S., Locke, J., ...,\&Kasari, C. (2010) Effects of Mindful Awareness Practices on Executive Functions in Elementary School Children, Journal of Applied School Psychology, 26, 70-95. doi: 10.1080/15377900903379125

Hornman, J., de Winter, A. F., Kerstjens, J. M., Bos, A. F., \&Reijneveld, S. A. (2016).Emotional and behavioral problems of preterm and full-term children at school entry.Pediatrics, e20152255.doi: 10.1542/peds.2015-2255

Hughes, C.H., \& Ensor, R.A. (2009). How do families help orhinder the emergence of early executive function? EnC. Lewis \& J.I.M. Carpendale (Eds.) Social interactionand the development of executive function.Newdirections in child and adolescent development(pp.35-50).London: Jossey-Bas

García-Bermúdez, O., Cruz-Quintana, F., Sosa, M.A., De la Cruz, J., Mañas, M.,\& Pérez-García, M. (2012). Alteraciones Neuropsicológicas y Emocionales en Niños Prematuros de Muy Bajo Peso al Nacer.[Neuropsychological and Emotional Disturbances in Premature Children of Very Low Birth Weight]Revista Argentina de CienciasdelComportamiento, 4, 3-10.

Gioia, G.A., Isquith, P.K., \& Guy S.C. (2000).Behavior Rating Inventory of Executive Function.Odessa, FL: PsychologicalAssessmentResources.

Hornman, J., de Winter, A. F., Kerstjens, J. M., Bos, A. F., \&Reijneveld, S. A. (2016).Emotional and behavioral problems of preterm and full-term children at school entry.Pediatrics, e20152255.doi: 10.1542/peds.2015-2255 
EF intervention in preterm children

Klingberg, T., Fernell, M.D., Olesen, P.J., Johnson, M.,Gustavsson, P., Dahlstrom, K., ...,\& Westerberg, H. (2005).Computarized training ofworking memory in children with ADHD.Arandomized, controlled trial. American Academy ofChild and Adolescence Psychiatry, 44, 177-186.

Lezak, M.D. (2004). Neuropsychological assessment. New York: Oxford University Press.

Lhaugen, G. C., Gramstad, A., Evensen, KA.,Martinussen, M., Lindqvist, S., Indredavik, M., ...,\&Skranes, J.(2010). Cognitive profile in young adults born preterm at very low birthweight.Developmental Medicine \& Child Neurology, 52, 1133-1138.doi:10.1111/j.1469-8749.2010.03743.x

Liu, L., Oza, S., Hogan, D., Chu, Y., Perin, J., Zhu, J., ... \& Black, R. E. (2016). Global, regional, and national causes of under-5 mortality in 2000-15: an updated systematic analysis with implications for the Sustainable Development Goals. The Lancet, 388, 3027-3035. doi: 10.1016/S0140-6736(16)31593-8

Loe, I. M., Lee, E. S., Luna, B. \&Feldman, H. M. (2011).Behavior problems of 9-16 year old preterm children: Biological, sociodemographic, and intellectual contributions. Early Human Development, 87, 247252.doi:10.1016/j.earlhumdev.2011.01.023

Maggiolo, M., Valera, V., Arancibia, C.,\& Ruíz, F. (2014). Dificultades de lenguaje en niños preescolares con antecedente de prematuridad extrema. [Language difficulties in preschool children with a history of extreme prematurity] Revistachilena de pediatría, 85, 319-327 doi:10.4067/S037041062014000300008

Mathiasen, R., Hansen, B. M., Forman, J. L., Kessing, L. V.,\& Greisen, G. (2011).The risk of psychiatric disorders in individuals born prematurely in Denmark from 
EF intervention in preterm children

1974 to 1996.ActaPediátrica, 100, 691-699.doi:10.1111/j.1651-

2227.2011.02136.x

Matthew, C., Davidson, M.C., Amso, D., Anderson, L.C. \& Diamond, A. (2006).

Development of cognitive control and executive functions from 4 to 13 years:

Evidence from manipulations of memory, inhibition, and task switching.

Neuropsychologia, 11, 2037-

2078.doi: 10.1016/j.neuropsychologia.2006.02.006

Miyake, A., Friedman, N.P., Emerson, M.J., Witzki, A.H., Howerter, A.,\& Wager, T (2000). The unity and diversity of executive functions and their contributions to complex 'frontal lobe' tasks: a latent variable analysis. Cognitive Psychiatry, 4, 49-100.doi:10.1006/cogp.1999.0734.

McCandliss, B.D., Beck, I.L., Sandak, R., \&Perfetti, C. (2003).Focusing attention on decoding for children with poorreading skills: design and preliminary tests of the WordBuilding Intervention. Scientific Studies of Reading, 7,75-104.

Nadler, R., Cordy, M., Stengel, J., Segal, Z. V., \& Hayden, E. P. (2017). A brief mindfulness practice increases self-reported calmness in young children: A pilot study. Mindfulness, 8, 1088-1095. doi: 10.1007/s12671-017-0685-2

Narberhaus, A., Pueyo-Benito, R., Segarra-Castells, M.D., Perapoch-López, J., BotetMussons, F., Junqué, C. ...\&Sánchez, H.L. (2007).Disfuncionescognitivas a largo plazorelacionadas con la prematuridad.[Long-term cognitive dysfunctions related to prematurity]Revista de Neurología, 45 (4),224-228.

Narberhaus, A., Segarra, D., Caldú, X., Giménez, M., Junqué, C., Pueyo, R., \&Botet, F. (2007). Gestational age at preterm birth in relation tocorpus callosum and general cognitive outcome in adolescents.Journalof Child Neurology, 22, 761765. 
EF intervention in preterm children

Nogueira-Cruz, F., Laynez-Rubio, C. Cruz-Quintana, F.,\& Pérez-García, M. (2012).

Neuropsychological evaluation of high-risk children from birth to seven years of age.The Spanish Journal of Psychology, 15, 101-111.

Ortiz-Mantilla, S., Choudhury, N., Leevers, H., \&Benasich, A.A. (2008).Understanding language and cognitive deficits in very low birth weightchildren. DevopmentalPsychobiology, 50, 107-126.

Perales, J. C., Nogueira-Cruz, J., Cruz-Quintana, F., Laynez-Rubio, C., Verdejo-García, A., \& Pérez-García, M. (2014). The role of motor impulsivity in socioemotional adjustment in high-risk seven year old children and healthy controls: A follow-up study. Anales de Psicología, 30, 221-231.

Portellano, J. A., Mateos, R. \& Martínez, R. (2000). Cuestionario de Madurez Neuropsicológica Infantil (CUMANIN).[ChildhoodNeuropsychologicalMaturityQuestionnaire (CUMANIN)] Madrid: TEA Ediciones.

Reijneveld, S. A., De Kleine, M. J. K. \& Van de Baar, A. L. (2006). Behavioral and emotional problems in very preterm and very low birthweight infants at age 5 years.Archives of Disease in Childhood Fetal Neonatal, 91, 423428.doi: 10.1136/adc.2006.093674

Saavalainen, P., Luoma, L., Bowler, D., Timonen, T., Maatta, S., Laukkanen, E., \&Herrgard, E. (2006).Naming skills of children bornpreterm in comparison with their term peers at the ages of 9 and 16years. Developmental Medicine and ChildNeurology, 48, 28-32.

Sastre-Riba, S. (2009). Prematuridad: análisis y seguimiento de las funciones ejecutivas. [Prematurity: analysis and follow-up of executive functions] Revista de Neurología, 48, S113-S111. 
EF intervention in preterm children

Segretin, M. S., Hermida, M. J., Prats, L. M., Fracchia, C. S., Colombo, J. A., \&Lipina, S. J. (2016). Estimulación de procesos cognitivos de control en niños de cuatro años: comparaciones entre formatos individual y grupal de intervención. [Stimulation of cognitive control processes in four-year-old children: comparisons between individual and group intervention formats] Revista Argentina de CienciasdelComportamiento, 8(3), 48-60

Shonkoff, J. P. (2010). Building a New Biodevelopmental Framework to Guide the Future of Early Childhood Policy.Child Development, 81, 357-367. doi: 10.1111/j.1467-8624.2009.01399.x.

Shonkoff, J. P., Richter, L., Van der Gaag, J.,\& Zulfiqar A. B. (2012). An Integrated Scientific Framework for Child Survival and Early Childhood development. JournalPediatrics, 129, 1-13. doi: 10.1542/peds.2011-0366.

Shonkoff, J. P., Siegel, B. S, Dobbins, M. I., Earls, M. F., Garner, A. S., McGuinn, L., ...,\& Wood, D. L. (2011). Early Childhood Adversity, Toxic Stress, and the Role of the Pediatrician: Translating Developmental Science Into Lifelong Health. Journal Pediatrics, 129, 224-231.

doi: $10.1542 /$ peds.2011-2662

Stevens, C., Fanning, J., Coch, D., Sanders, L., \& Neville, H.(2008). Neural mechanisms of selective auditory attention are enhanced by computerized training:electrophysiological evidence from language-impairedand typically developing children. Brain Research, 1205, 55-69

Spittle, A. J., Barton, S., Treyvaud, K., Molloy, C. S., Doyle, L. W., \& Anderson, P. J. (2016). School-age outcomes of early intervention for preterm infants and their parents: a randomized trial. Pediatrics, 138(6), e20161363. 
EF intervention in preterm children

Spittle, A., \&Treyvaud, K. (2016). The role of early developmental intervention to influence neurobehavioral outcomes of children born preterm. Seminars in perinatology, 40,542-548.

Temple, E., Deutsch, G.K., Poldrack, R.A., Miller, S.L., Tallal, P.,Merzenich, M.M., \&Gabrieli, J.D. (2003). Neural deficitsin children with dyslexia ameliorated by behavioralremediation: evidence from functional MRI.Proceedings of the National Academy of Sciences, 100, 2860-2865.

Thorell, L.B., Lindqvist, S., Bergman Nutley, S., Bohlin, G., \&Klingberg, T. (2009). Training and transfer effects ofexecutive functions in preschool children.DevelopmentalScience, 12, 106-113.

Tideman, E. (2000). Longitudinal follow-up of children born preterm:Cognitive development at age 19. Early Human Development, 58, 81- 90.

Veleiro, A. \&Peralbo, M. (2014).Validación de la versión para profesorado del BRIEFP en una muestra escolar de Galicia (España). [Validation of theteachers' version of the BRIEF-P in a sample of students in Galicia (Spain)]Revista de Estudios e Investigación en Psicología y Educación, 2.doi: 10.17979/reipe.2014.1.2.75

World Health Organization (2016).Preterm births. Available in http://www.who.int/mediacentre/factsheets/fs363/es/

Wilson, A.J., Revkin, S.K., Cohen, D., Cohen, L., \&Dehaene, S. (2006).An open trial assessment of The Number Race,an adaptive computer game for remediation ofdyscalculia. Behavioral and Brain Functions, 2, 20-28.

Wocadlo, C., \&Rieger, I. (2007).Phonology, rapid naming and academicachievement in very preterm children at eight years of age.EarlyHuman Development, 83, 367377. 
EF intervention in preterm children

Table 1. Mean, standard deviation, and analysis of the differences between the

neuropsychological intervention group and the curricular intervention group in

sociodemographic, clinical, habits and test variables of Cattell

\begin{tabular}{|c|c|c|c|c|c|c|}
\hline \multirow[t]{2}{*}{$\begin{array}{l}\text { Clinical and sociodemographic } \\
\text { variables }\end{array}$} & \multicolumn{2}{|c|}{$\begin{array}{c}\text { Group NIG } \\
\mathbf{N}=\mathbf{3 6} \\
\end{array}$} & \multicolumn{2}{|c|}{$\begin{array}{c}\text { Group CIG } \\
\mathrm{N}=32 \\
\end{array}$} & \multirow[b]{2}{*}{ to $\chi^{2}$} & \multirow[b]{2}{*}{$p$} \\
\hline & $\mathrm{MoN}$ & SD o $\%$ & $\mathrm{MoN}$ & $\mathrm{SD}$ o $\%$ & & \\
\hline Age of child (Months) & 61.01 & 7.17 & 59.21 & 5.21 & 1.06 & .291 \\
\hline Sex of child & & & & & 1.99 & .158 \\
\hline Boy & 13 & $36.1 \%$ & 17 & $53.1 \%$ & & \\
\hline Girl & 23 & $63.9 \%$ & 15 & $46.9 \%$ & & \\
\hline Weight of child (Kg) & 18.04 & 2.71 & 17.65 & 2.75 & 0.588 & .559 \\
\hline Type of birth & & & & & 2.20 & .333 \\
\hline Natural & 15 & $41.7 \%$ & 19 & $59.4 \%$ & & \\
\hline Cesarean & 17 & $47.2 \%$ & 10 & $31.3 \%$ & & \\
\hline Use of forceps & 4 & $11.1 \%$ & 3 & $9.4 \%$ & & \\
\hline Gestation period (Weeks) & 35.18 & 1.51 & 34.73 & 1.84 & 1.09 & .280 \\
\hline School adaptation & & & & & .89 & .345 \\
\hline Good & 21 & $58.3 \%$ & 15 & $46.9 \%$ & & \\
\hline Poor & 15 & $41.7 \%$ & 17 & $53.1 \%$ & & \\
\hline Chronic illness & & & & & .05 & .822 \\
\hline Yes & 6 & $16.7 \%$ & 6 & $18.8 \%$ & & \\
\hline No & 30 & $83.3 \%$ & 26 & $81.3 \%$ & & \\
\hline Special diet & & & & & .01 & .903 \\
\hline Yes & 2 & $5.6 \%$ & 2 & $6.3 \%$ & & \\
\hline No & 34 & $94.4 \%$ & 30 & $93.8 \%$ & & \\
\hline Continuous medication & & & & & .30 & .584 \\
\hline Yes & 4 & $11.1 \%$ & 5 & $15.6 \%$ & & \\
\hline No & 32 & $88.9 \%$ & 27 & $84.4 \%$ & & \\
\hline Child's hours of sleep & 10.50 & 1.05 & 10.59 & 1.01 & -.373 & .711 \\
\hline Mother smokes & & & & & 1.10 & .294 \\
\hline Yes & 8 & $22.2 \%$ & 4 & $12.5 \%$ & & \\
\hline No & 28 & $77.8 \%$ & 28 & $87.5 \%$ & & \\
\hline Mother's age (years) & 38.917 & 39.00 & 4.581 & 4.846 & -.073 & .942 \\
\hline Mother's age at pregnancy (years) & 33.750 & 4.305 & 33.719 & 4.034 & .031 & .976 \\
\hline Socioeconomic status & & & & & 1.92 & .382 \\
\hline Low & 0 & $0 \%$ & 1 & $3.1 \%$ & & \\
\hline Medium & 17 & $47.2 \%$ & 18 & $56.3 \%$ & & \\
\hline High & 19 & $52.8 \%$ & 13 & $40.6 \%$ & & \\
\hline Mother's level of education & & & & & 5.55 & .136 \\
\hline $\begin{array}{ll}\text { Primary }\end{array}$ & 4 & $11.1 \%$ & 10 & $31.3 \%$ & & \\
\hline $\begin{array}{r}\text { Secondary Education/Professional } \\
\text { Training }\end{array}$ & 8 & $22.2 \%$ & 6 & $18.8 \%$ & & \\
\hline University & 15 & $41.7 \%$ & 7 & $21.9 \%$ & & \\
\hline Doctorate & 9 & $25 \%$ & 9 & $28.1 \%$ & & \\
\hline Cattell scores of the mother(DS) & 28.417 & 4.285 & 28.531 & 3.408 & -.121 & .904 \\
\hline
\end{tabular}

Note. NIG $=$ Neuropsychological (PEFEN) Intervention Group; $C I G=$ Curriculum

Intervention Group, $M=$ Mean, $S D=$ Standard deviation, $D S=$ Direct Score. 
EF intervention in preterm children

Table 2. Means, standard deviations, effect size and analysis of the differences for the BENCI factors.

\begin{tabular}{|c|c|c|c|c|c|c|c|c|c|}
\hline \multirow{2}{*}{$\begin{array}{c}\text { BENCI } \\
\text { variables }\end{array}$} & \multirow{2}{*}{ Group } & \multicolumn{2}{|c|}{ Pre } & \multicolumn{2}{|c|}{ Post } & \multirow[b]{2}{*}{$d$} & & \multirow[b]{2}{*}{$F$} & \multirow[b]{2}{*}{$p$} \\
\hline & & M & SD & M & SD & & & & \\
\hline \multirow{3}{*}{$\begin{array}{l}\text { Figure } \\
\text { comprehension } \\
\text { (Verbal) }\end{array}$} & NIG & 7.86 & 1.69 & 8.53 & 1.59 & 0.40 & Time & 8.90 & $.004^{* *}$ \\
\hline & CIG & 7.91 & 1.35 & 8.69 & 1.09 & 0.63 & Group & .15 & .695 \\
\hline & & & & & & & TimeXGroup & .06 & .814 \\
\hline \multirow{3}{*}{$\begin{array}{l}\text { Image } \\
\text { comprehension } \\
\text { (Verbal) }\end{array}$} & NIG & 7.67 & 2.18 & 7.89 & 1.19 & 0.13 & Time & 6.03 & $.017 *$ \\
\hline & CIG & 7.66 & 0.83 & 8.62 & 1.01 & 1.06 & Group & 2.15 & .157 \\
\hline & & & & & & & TimeXGroup & 2.37 & .129 \\
\hline \multirow{3}{*}{$\begin{array}{l}\text { Continuous } \\
\text { execution }\end{array}$} & NIG & 60.22 & 7.53 & 65.14 & 5.13 & 0.77 & Time & 2.55 & .115 \\
\hline & $\mathrm{CIG}$ & 61.09 & 9.31 & 60.75 & 8.63 & 0.03 & Group & 1.89 & .174 \\
\hline & & & & & & & TimeXGroup & 3.37 & .071 \\
\hline \multirow{3}{*}{$\begin{array}{l}\text { Continuous } \\
\text { execution (TR) }\end{array}$} & NIG & 1.03 & 0.15 & 0.96 & 0.29 & 0.37 & Time & 2.33 & .131 \\
\hline & CIG & 0.97 & 0.12 & 0.92 & 0.35 & 0.23 & Group & 1.41 & .240 \\
\hline & & & & & & & TimeXGroup & .09 & .765 \\
\hline \multirow{3}{*}{ Phonetic fluidity } & NIG & 1.31 & 1.49 & 3.72 & 2.06 & 1.36 & Time & 47.16 & $<.001 * * *$ \\
\hline & $\mathrm{CIG}$ & 1.12 & 1.38 & 2.37 & 1.54 & 0.85 & Group & 6.51 & $.013^{*}$ \\
\hline & & & & & & & TimeXGroup & 4.77 & $.032 *$ \\
\hline \multirow{3}{*}{ Semantic fluidity } & NIG & 5.14 & 2.56 & 7.72 & 2.47 & 1.03 & Time & 30.13 & $<.001 * * *$ \\
\hline & CIG & 5.44 & 2.33 & 6.94 & 2.17 & 0.66 & Group & .29 & .589 \\
\hline & & & & & & & TimeXGroup & 2.12 & .150 \\
\hline \multirow{3}{*}{ Working memory } & NIG & 4.72 & 3.13 & 11.14 & 6.23 & 1.37 & Time & 40.46 & $<.001 * * *$ \\
\hline & $\mathrm{CIG}$ & 4.56 & 1.85 & 8.03 & 5.35 & 0.96 & Group & 4.43 & $.039 *$ \\
\hline & & & & & & & TimeXGroup & 3.60 & $.062 *$ \\
\hline \multirow{3}{*}{$\begin{array}{l}\text { Verbal memory } \\
\left(1^{\text {st }} \text { test }\right)\end{array}$} & NIG & 2.03 & 1.58 & 3.97 & 1.34 & 1.45 & Time & 67.39 & $<.001 * * *$ \\
\hline & CIG & 1.97 & 1.66 & 4.22 & 1.62 & 1.37 & Group & .11 & .735 \\
\hline & & & & & & & TimeXGroup & .36 & .552 \\
\hline \multirow{3}{*}{$\begin{array}{l}\text { Verbal Memory } \\
\left(3^{\text {rd }} \text { test }\right)\end{array}$} & NIG & 4,528 & 2.06 & 5.33 & 2.10 & 0.39 & Time & 6.63 & $.012 *$ \\
\hline & CIG & 3.72 & 2.16 & 4.94 & 2.01 & 0.97 & Group & 3.56 & .063 \\
\hline & & & & & & & TimeXGroup & .28 & .601 \\
\hline \multirow{3}{*}{$\begin{array}{l}\text { Verbal Memory } \\
\text { (Delayed) }\end{array}$} & NIG & 2.47 & 1.87 & 5.08 & 2.16 & 1.30 & Time & 39.83 & $<.001 * * *$ \\
\hline & CIG & 2.91 & 2.07 & 4.28 & 2.29 & 0.36 & Group & 0.21 & .647 \\
\hline & & & & & & & TimeXGroup & 3.83 & $.055^{*}$ \\
\hline \multirow{3}{*}{$\begin{array}{l}\text { Verbal memory } \\
\text { (Recognition) }\end{array}$} & NIG & 12.75 & 3.11 & 13.72 & 4 & 0.27 & Time & 4.51 & $.037^{*}$ \\
\hline & CIG & 13.47 & 3.02 & 14.94 & 3.26 & 0.46 & Group & 2.70 & .105 \\
\hline & & & & & & & TimeXGroup & .19 & .667 \\
\hline \multirow{3}{*}{$\begin{array}{l}\text { Abstract } \\
\text { reasoning }\end{array}$} & NIG & 7.75 & 2.90 & 10 & 4.50 & 0.60 & Time & 19.95 & $<.001 * * *$ \\
\hline & $\mathrm{CIG}$ & 7.37 & 2.88 & 11.47 & 5.54 & 0.97 & Group & .62 & .435 \\
\hline & & & & & & & TimeXGroup & 1.68 & .199 \\
\hline \multirow{2}{*}{$\begin{array}{l}\text { Visual memory } \\
\text { (immediate) }\end{array}$} & NIG & 3.64 & 1.97 & 5.44 & 2.06 & 0.90 & Time & 24.41 & $<.001 * * *$ \\
\hline & CIG & 3.12 & 1.83 & 4.78 & 2.14 & 0.83 & Group & 3.03 & .086 \\
\hline
\end{tabular}


EF intervention in preterm children

\begin{tabular}{lcccccccccc}
\hline & & & & & & & TimeXGroup & .04 & .832 \\
$\begin{array}{l}\text { Visual memory } \\
\text { (Delayed) }\end{array}$ & NIG & 2.36 & 1.93 & 4.89 & 1.58 & 1.44 & Time & 34.18 & $<.001 * * *$ \\
& CIG & 2.06 & 1.88 & 3.03 & 1.89 & 0.51 & Group & 10.89 & $.002 * *$ \\
& & & & & & & TimeXGroup & 6.79 & $.011^{*}$ \\
$\begin{array}{l}\text { Visual memory } \\
\text { (recognition) }\end{array}$ & NIG & 38.53 & 9.21 & 41.78 & 6.85 & 0.40 & Time & 10.14 & $.002^{* *}$ \\
& CIG & 38.31 & 8.42 & 43.41 & 4.81 & 0.77 & Group & .30 & .584 \\
& & & & & & & TimeXGroup & .49 & .484 \\
\hline
\end{tabular}

Note: $* p<.05, * * p<.01, * * * p<.001 d=$ mild $(0.2)$, moderate $(0.5) \&$ large $(0.8)$ 
EF intervention in preterm children

Table 3. Means, standard deviations, effect size, and analysis of the differences for the

CUMANIN factors

\begin{tabular}{|c|c|c|c|c|c|c|c|c|c|}
\hline \multirow{2}{*}{$\begin{array}{l}\text { Variables } \\
\text { CUMANIN }\end{array}$} & \multirow{2}{*}{ Group } & \multicolumn{2}{|c|}{ Pre } & \multicolumn{2}{|c|}{ Post } & \multirow[b]{2}{*}{$d$} & & \multirow{2}{*}{$F$} & \multirow{2}{*}{$p$} \\
\hline & & M & DT & M & DT & & & & \\
\hline \multirow{3}{*}{ Psychomotricity } & NIG & 8.11 & 2.12 & 8.28 & 1.89 & 0.08 & Time & 5.69 & $.020 *$ \\
\hline & CIG & 7.09 & 2.08 & 8.19 & 2.10 & 0.52 & Group & 1.72 & .194 \\
\hline & & & & & & & TimeXGroup & 3.08 & .084 \\
\hline \multirow{3}{*}{$\begin{array}{l}\text { Language } \\
\text { Articulation }\end{array}$} & NIG & 8.69 & 3.70 & 10.69 & 3.41 & 0.56 & Time & 64.73 & $<.001 * * *$ \\
\hline & CIG & 7.75 & 4.26 & 10.37 & 3.86 & 0.64 & Group & .52 & .474 \\
\hline & & & & & & & TimeXGroup & 1.18 & .281 \\
\hline \multirow{3}{*}{$\begin{array}{l}\text { Language } \\
\text { expression }\end{array}$} & NIG & 2.14 & 1.22 & 2.78 & 1.10 & 0.55 & Time & 19.56 & $<.001 * * *$ \\
\hline & CIG & 2.09 & 1.25 & 2.62 & 1.10 & 0.45 & Group & .15 & .695 \\
\hline & & & & & & & TimeXGroup & .176 & .685 \\
\hline \multirow{3}{*}{$\begin{array}{l}\text { Language } \\
\text { comprehension }\end{array}$} & NIG & 4.06 & 2.18 & 5.33 & 1.85 & 0.63 & Time & 31.74 & $<.001 * * *$ \\
\hline & CIG & 3.62 & 1.84 & 4.81 & 2.08 & 0.60 & Group & 1.21 & .276 \\
\hline & & & & & & & TimeXGroup & .22 & .837 \\
\hline \multirow{3}{*}{ Spatial structure } & NIG & 8.69 & 2.24 & 11 & 2.23 & 1.03 & Time & 41.06 & $<.001 * * *$ \\
\hline & CIG & 8.56 & 2.14 & 10 & 2.51 & 0.61 & Group & 1.44 & .234 \\
\hline & & & & & & & TimeXGroup & 2.21 & .142 \\
\hline \multirow{3}{*}{ Visuoperception } & NIG & 7.67 & 3.73 & 10.36 & 3.91 & 0.70 & Time & 74.44 & $<.001 * * *$ \\
\hline & CIG & 7.56 & 2.47 & 9.66 & 2.39 & 0.86 & Group & .30 & .585 \\
\hline & & & & & & & TimeXGroup & 1.17 & .283 \\
\hline \multirow{3}{*}{ Memory } & NIG & 4.17 & 1.65 & 5.75 & 1.71 & 0.94 & Time & 7.95 & $<.001 * * *$ \\
\hline & $\mathrm{CIG}$ & 4.37 & 1.79 & 5.34 & 2.25 & 0.47 & Group & .09 & .769 \\
\hline & & & & & & & TimeXGroup & 1.04 & .311 \\
\hline \multirow{3}{*}{ Rhythm } & NIG & 2.33 & 1.55 & 3.36 & 1.38 & 0.70 & Time & 9.23 & $.003 * *$ \\
\hline & CIG & 2.41 & 1.48 & 2.31 & 1.47 & 0.06 & Group & 2.29 & .135 \\
\hline & & & & & & & TimeXGroup & 13.31 & $.001 *$ \\
\hline \multirow{3}{*}{ Verbal fluidity } & NIG & 0.10 & 1.38 & 3.42 & 1.25 & 2.53 & Time & 85.72 & $<.001 * * *$ \\
\hline & CIG & 0.62 & 1.24 & 1.78 & 1.64 & 0.80 & Group & 13.07 & $.001 * *$ \\
\hline & & & & & & & TimeXGroup & 10.97 & $.002 * *$ \\
\hline \multirow{3}{*}{ Attention } & NIG & 13.28 & 3.92 & 15.97 & 3.46 & 0.73 & Time & 15.80 & $.001 * *$ \\
\hline & CIG & 10.78 & 4.43 & 11.72 & 3.52 & 0.23 & Group & 17.15 & $<.001 * * *$ \\
\hline & & & & & & & TimeXGroup & 3.70 & .059 \\
\hline \multirow[t]{3}{*}{ Total EF } & NIG & 59.72 & 14.31 & 76.97 & 12.98 & 1.26 & Time & 220.45 & $<.001 * * *$ \\
\hline & CIG & 54.06 & 11.48 & 66.81 & 12.60 & 1.01 & Group & 7.07 & $.010^{*}$ \\
\hline & & & & & & & TimeXGroup & 4.96 & $.029 *$ \\
\hline
\end{tabular}

Nota: $* p<.05, * * p<.01, * * * p<.001, d=$ mild $(0.2)$, moderate $(0.5) \&$ large $(0.8)$ 
EF intervention in preterm children

Table 4. Means, standard deviations, effect size, and analysis of the differences for the BRIEF-P factors.

\begin{tabular}{|c|c|c|c|c|c|c|c|c|c|}
\hline \multirow{2}{*}{$\begin{array}{l}\text { BRIEF-P } \\
\text { Variables }\end{array}$} & \multirow{2}{*}{ Group } & \multicolumn{2}{|c|}{ Pre } & \multicolumn{2}{|c|}{ Post } & \multirow{2}{*}{$d$} & & \multirow{2}{*}{$F$} & \multirow{2}{*}{$p$} \\
\hline & & $M$ & $S D$ & $M$ & $S D$ & & & & \\
\hline \multirow[t]{3}{*}{ Inhibition } & NIG & 9.19 & 6.62 & 9.19 & 6.29 & 0.00 & Time & 5.18 & $.026^{*}$ \\
\hline & CIG & 11.37 & 5.87 & 8.91 & 6.51 & 0.39 & Group & .43 & .514 \\
\hline & & & & & & & TimeXGroup & 5.19 & $.026^{*}$ \\
\hline \multirow[t]{3}{*}{ Flexibility } & NIG & 2.89 & 3.39 & 2.61 & 2.22 & 0.09 & Time & 3.07 & .085 \\
\hline & CIG & 4.31 & 3.37 & 3.31 & 3.05 & 0.31 & Group & 2.75 & .102 \\
\hline & & & & & & & TimeXGroup & .98 & .326 \\
\hline \multirow{3}{*}{$\begin{array}{l}\text { Emotional } \\
\text { control }\end{array}$} & NIG & 4.92 & 4.32 & 4.80 & 3.88 & 0.02 & Time & 1.76 & .190 \\
\hline & $\mathrm{CIG}$ & 5.72 & 4.57 & 4.84 & 3.38 & 0.22 & Group & .21 & .648 \\
\hline & & & & & & & TimeXGroup & 1.05 & .308 \\
\hline \multirow{3}{*}{$\begin{array}{l}\text { Working } \\
\text { memory }\end{array}$} & NIG & 8.55 & 6.49 & 8.58 & 7.14 & 0.00 & Time & .95 & .332 \\
\hline & CIG & 9.53 & 5.46 & 8.56 & 6 & 0.17 & Group & .11 & .745 \\
\hline & & & & & & & TimeXGroup & 1.07 & .305 \\
\hline \multirow[t]{3}{*}{ Planning } & NIG & 5.58 & 3.33 & 5.30 & 4.12 & 0.07 & Time & .49 & .486 \\
\hline & CIG & 5.87 & 3.60 & 5.69 & 3.48 & 0.05 & Group & .17 & .684 \\
\hline & & & & & & & TimeXGroup & 1.07 & .305 \\
\hline \multirow[t]{3}{*}{ Coherence } & NIG & 3.42 & 3.51 & 3.53 & 2.96 & 0.03 & Time & .42 & .518 \\
\hline & CIG & 3.31 & 2.43 & 2.81 & 2.52 & 0.20 & Group & .41 & .525 \\
\hline & & & & & & & TimeXGroup & 1.05 & .310 \\
\hline
\end{tabular}

